\title{
Sistem Komunikasi Audio dengan Teknologi Visible Light Communication (VLC) Menggunakan Laser Led
}

\author{
Atik Charisma $^{1^{*}}$, Rizky Nur Akbar Setiawan ${ }^{2}$, Een Taryana ${ }^{3}$, Hajiar Yuliana ${ }^{4}$, Alifa Rike \\ Indriani $^{5}$ \\ 1,2,3,4,5 Jurusan Teknik Elektro, Fakultas Teknik, Universitas Jenderal Achmad Yani \\ 1,2,3,4,5J1. Terusan Jend. Sudirman, Cibeber, Kec. Cimahi Selatan., Kota Cimahi, Jawa Barat \\ 40531, Indonesia \\ e-mail: ${ }^{1}$ atik.charisma@lecture.unjani.ac.id*, ${ }^{2}$ rizkynuras@gmail.com, \\ 3eentaryana@lecture.unjani.ac.id,hajiar.yuliana@lecture.unjani.ac.id, \\ 5rikealifa21@gmail.com
}

\begin{abstract}
Abstrak
Kegiatan masyarakat di era sekarang yang serba digital menggunakan teknologi tanpa kabel (wireless). Teknologi tanpa kabel menjadi andalan komunikasi, namun seiring perkembangann zaman, ada sebuah teknologi tanpa kabel dengan memanfaatkan cahaya tampak. Teknologi ini dikenal dengan istilah visible light communication (VLC). Sistem VLC terdiri dari bagian transmitter dan receiver. Transmitter berupa komponen-komponen elektronika yang terintegrasi dengan cahaya tampak sebagai media transmisi. Pada penelitian ini membuat bagian transmitter dan receiver untuk komunikasi audio. Cahaya tampak sebagai media transmisi menggunakan laser led karena cahaya dari laser led ini lebih fokus dan pancaran cahayanya lebih jauh dibandingkan dengan yang lain. Sedangkan di sisi receiver menggunakan solar panel sebagai penerima sinyal informasi yang dikirimkan. Penelitian ini berhasil membuat sebuah sistem komunikasi audio berbasis visible light communication. Variasi jarak antara transmitter dan receiver mempengaruhi kualitas suara yang diterima. Pada jarak $500 \mathrm{~cm}$ kualitas suara yaitu 99,2 dB pada kondisi gelap dan 99,1 dB kondisi terang. Perubahan sudut pancar transmitter terhadap receiver juga mempengaruhi hasil kualitas suara. Kualitas suara terbaik pada sudut $90^{\circ}$ di kondisi terang dengan jarak $50 \mathrm{~cm}$ sebesar 97,9 dB sedangkan di kondisi gelap dengan jarak $50 \mathrm{~cm}$ pada sudut $100^{\circ}$ sebesar $98,1 \mathrm{~dB}$.
\end{abstract}

Kata Kunci: audio, VLC, laser led, solar panel

\begin{abstract}
The people activities in today's digital era use wireless technology. Wireless technology has become the mainstay of communication, but along with the times, there is a wireless technology that uses visible light. This technology is known as visible light communication $(V L C)$. The VLC system consist of transmitter and receiver. Transmitters are electronic components that are integrated with visible light as a transmission medium. In this study, the transmitter and receiver are made for audio communication. Visible light as a transmission medium uses an LED laser because the light from this LED laser is more focused and the light beam is farther away than the others. While on the receiver side using a solar panel as a receiver of the information signal that is sent. This research succeeded in making an audio communication system based on visible light communication. Variations in the distance between the transmitter and receiver affect the quality of the received sound. At a distance of $500 \mathrm{~cm}$ in dark conditions, the sound quality is $99.2 \mathrm{~dB}$ in light conditions and $99.1 \mathrm{~dB}$. Changes in the beam angle of tranmitter to receiver also affect the sound quality. The best sound quality at an angle of 900 in bright conditions with a distance of $50 \mathrm{~cm}$ is $97.9 \mathrm{~dB}$ while in dark conditions with a distance of $50 \mathrm{~cm}$ at an angle of 1000 is $98.1 \mathrm{~dB}$.
\end{abstract}

Keywords : audio, VLC, laser led, solar panel 


\section{Pendahuluan}

Wireless teknologi pada saat ini menjadi hal yang sangat penting untuk transfer informasi dengan jarak jauh tanpa kabel (wireless)[1]. Wireless Fidelity (WiFi) merupakan salah satu komunikasi tanpa kabel, selain WiFi teknologi tanpa kabel terdahulunya yaitu, bluetooth dan infrared. Komunikasi tanpa kabel lainya yaitu Light Fidelity (LiFi). Teknologi LiFi merupakan teknologi komunikasi nirkabel berkecepatan tinggi yang menggunakan cahaya tampak (visible light) untuk mengirimkan informasi. WiFi bekerja bergantung terhadap gelombang radio sedangkan $\mathrm{LiFi}$ bekerja menggunakan cahaya tampak (visible light)[2]. Verna dkk dalam penelitiannya [2] membandingkan teknologi WiFi dengan LiFi dengan tujuan untuk mencari kelemahan teknologi WiFi sehingga mengetahui dampaknya terhadap perkembangan lalu lintas komunikasi data terkini. LiFi menjadi solusi permasalahan bandwidth dengan mampu meningkatkan bandwidth hingga 100 kali lipat WiFi serta akses multiuser.

Sistem komunikasi dengan cahaya tampak dapat mengirimkan informasi berupa suara dan data (teks) dengan memanfaatkan perubahan tegangan dari amplituda suara[3]. Lain halnya informasi berupa teks memanfaatkan software untuk mengubah teks menjadi sinyal cahaya dengan sumber radiasi berupa LED di bagian pengirim. Sedangkan di bagian penerima terdapat photodetector serta software untuk mengubah cahaya tampak menjadi sinyal listrik berupa teks. Ukuran spektrum cahaya inframerah dan cahaya tampak apabila ditotal kira-kira 2600 kali ukuran seluruh spektrum frekuensi radio $300 \mathrm{GHz}[2]$. Visible light communication atau komunikasi menggunakan cahaya tampak memanfaatkan komponen dari cahaya tampak seperti LED, laser, phototransistor atau photodioeda sebagai media transmisi dengan panjang gelombang antara $375 \mathrm{~nm}(800 \mathrm{THz})-780 \mathrm{~nm}(400 \mathrm{THz})$ seperti pada Gambar 1.

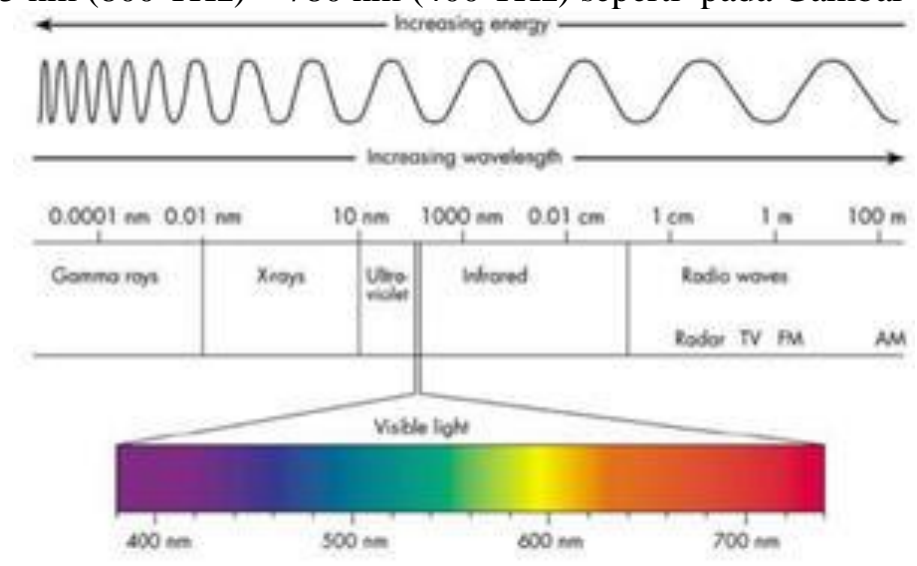

Gambar 1. Spektrum Cahaya Tampak[4].

Tabel 1 memperlihatkan perbandingan VLC dengan Near Field Communication (NFC) dan Bluetooth Low Energy (BLE). Keunggulan VLC terdapat pada bagian regulasi pemakaian pita komunikasi, bandwidth, kecepatan transmisi data, ketersediaan infrastruktur, dan faktor ketahanan terhadap interferensi elektromagnetik[5].

Penelitian berikutnya mengimplementasikan sistem $V L C$ yang berfokus pada layer fisik yakni pada bagian Analog Front-End (AFE). Sistem yang dirancang terdiri atas modul AFE transmitter sebagai modulator dan AFE receiver sebagai demodulator[8]. Pengiriman suara melalui LED dengan modulasi PWM[9] atau AM namun terdapat noise yang besar di bagian transmitter. Keuntungan dari lampu jenis LED ini dimanfaatkan sebagai media transmisi dengan harga yang lebih murah namun dengan kecepatan yang tinggi. VLC dapat diterapkan pada beberapa LED dengan frekuensi yang berbeda melalui transmisi di udara bebas[10]. Berdasarkan penelitian yang telah dipaparkan sebelumnya, maka pada penelitian ini merancang prototype sistem komunikasi audio dengan laser LED sebagai media transmitter yang mampu mengirimkan data audio mengugunakan sistem visible light communication dan diterima oleh solar panel sebagai receiver. Penelitian ini dilakukan pada indoor karena kalau outdoor akan ada interferensi dengan cahaya matahari. 
Tabel 1. Perbandingan NFC dan BLE dengan VLC[6][7]

\begin{tabular}{|c|c|c|c|}
\hline Parameter & NFC & BLE & VLC \\
\hline Sistem komunikasi & ISO/IEC 14443 & Bluetooth Core & IEEE 802.157 \\
\hline & $\begin{array}{l}\text { A\&B, JIS X-6319: } \\
4\end{array}$ & $\begin{array}{l}\text { Specification } 4.0 \text { / } \\
4.1 / 4.2\end{array}$ & VLCC JEITA CP-1223 \\
\hline Bandwidth & $13.56 \mathrm{MHz}$ & $2.4 \mathrm{GHz}$ & $\begin{array}{l}400 \mathrm{~nm}(750 \mathrm{THz})-700 \\
\mathrm{~nm}(428 \mathrm{THz})\end{array}$ \\
\hline $\begin{array}{l}\text { Regulasi pemakaian } \\
\text { frekuensi }\end{array}$ & $\begin{array}{l}\text { Teregulasi, } \\
\text { Bandwidth terbatas }\end{array}$ & $\begin{array}{l}\text { Teregulasi, } \\
\text { bandwidth terbatas }\end{array}$ & Tidak teregulasi \\
\hline $\begin{array}{l}\text { Kecepatan transmisi } \\
\text { data }\end{array}$ & $424 \mathrm{Kbits} / \mathrm{s}$ & $300 \mathrm{Kbits} / \mathrm{s}$ & $\mathrm{Mb} / \mathrm{s}-\mathrm{Gb} / \mathrm{s}$ \\
\hline Jarak transmisi data & $<10 \mathrm{~cm}$ & $<70 \mathrm{~m}$ & $<120 \mathrm{~m}$ \\
\hline $\begin{array}{l}\text { Kematangan } \\
\text { teknologi }\end{array}$ & Matang & Matang & Belum matang \\
\hline $\begin{array}{l}\text { Interferensi } \\
\text { gelombang } \\
\text { elektromagnetik }\end{array}$ & $\mathrm{Ya}$ & Ya & Tidak \\
\hline Infrastruktur & Acces point & Acces point & Perangkat penerangan \\
\hline Vision line & $\begin{array}{l}\text { Ya (kontak } \\
\text { langsung) }\end{array}$ & Tidak & $\begin{array}{l}\text { Ya / Tidak (dengan } \\
\text { konfigurasi LOS / non- } \\
\text { LOS) }\end{array}$ \\
\hline Konsumsi energi & Sangat rendah & Medium & $\begin{array}{l}\text { Rendah, medium, tinggi } \\
\text { (bergantung pada daya } \\
\text { LED yang dipakai) }\end{array}$ \\
\hline Interaksi mobilitas & Tidak ada & Luas & $\begin{array}{l}\text { Terbatas (sifat cahaya } \\
\text { tidak dapat menembus } \\
\text { objek padat) }\end{array}$ \\
\hline $\begin{array}{l}\text { Transmisi Machine- } \\
\text { to-Machine (M2M) }\end{array}$ & Bidirectional & Bidirectional & Bidirectional \\
\hline Resiko pemakaian & Tidak ada & $\begin{array}{l}\text { Ya (emisi sinyal } \\
\text { RF) }\end{array}$ & Kesehatan mata dan mood \\
\hline $\begin{array}{l}\text { Sensitivitas terhadap } \\
\text { noise }\end{array}$ & Tidak & Other users & Kondisi lingkungan \\
\hline
\end{tabular}

\section{Metode Penelitian}

Study literature menjadi langkah pertama dalam sebuah penelitian dengan mengumpulkan data - data serta membandingkan penelitian sebelumnya yang telah dipublikasikan (seminar, prosiding dan jurnal) baik pada skala nasional maupun internasional serta buku pedoman lainnya untuk mendapatkan data yang akurat[11]. Ada dua tahapan pada study literature yaitu state of the art dan studi pustaka[12]. VLC bisa diimplementasikan dengan dua cara, yaitu pertama dengan menghubungkan langsung antara master device ke rangkaian transmitter di mana data diterima oleh receiver dan sekaligus ditampilkan secara langsung. Kedua dengan mengkodekan data-data menggunakan perangkat Digital Signal Processing (DSP) dan data dimodulasi terlebih dahulu, baik modulasi digital atau analog. Implementasi VLC yang menggunakan pendekatan pertama (tanpa modulasi), diantaranya dilakukan oleh [13] yang mendemonstrasikan pengiriman sinyal suara berbasis VLC.

Langkah awal dari sebuah penelitian berupa pembuatan hardware yakni dengan mensimulasikan beberapa komponen elektronika agar ketika diimplementasikan mendapatkan hasil yang sesuai dengan spesifikasi[14]. Maka penelitian ini terlebih dahulu mensimulasikan tegangan yang diterima oleh sistem penerima. Pada penelitian ini mengimplementasi VLC dengan cara yang pertama yakni terdiri dari dua bagian utama yaitu transmitter dan receiver seperti tampak di Gambar 2. Input penelitian berupa audio sebagai sumber informasi yang 
diperoleh melalui laptop. Kemudian informasi ini dikirimkan melalui transmitter berupa cahaya tampak dan diterima di bagian receiver yakni solar panel mini. Sinyal yang diterima oleh solar panel kemudian dikuatkan terlebih dahulu menggunakan modul amplifier agar mempertahakankan kualitas suara yang diterima tetap bagus.

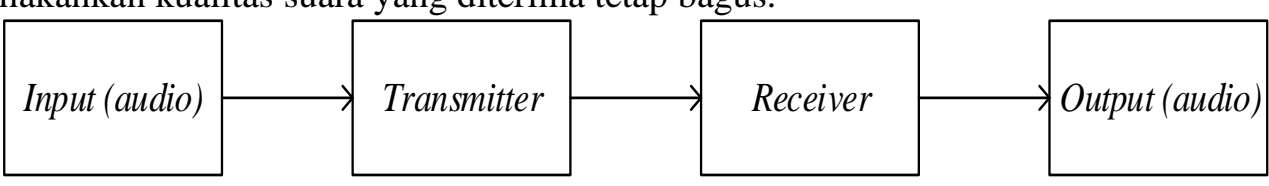

Gambar 2. Blok Diagram Sistem.

Pengujian pada blok transmitter dan receiver dengan memastikan tegangan keluaran pada transmitter stabil di 4 Volt. Hal ini perlu dilakukan agar tegangan yang diterima di bagian receiver sesuai sehingga informasi dapat diterima. Setelah kedua blok diuji secara terpisah, maka kedua blok tersebut diuji secara bersama. Pengujian dilakukan dengan mengirimkan audio melalui laser led kemudian diterima oleh panel surya serta audio tersebut dikeluarkan melalui speaker.

Perancangan sistem pengiriman data dideskripsikan di Gambar 3 pada bagian block input audio berupa data sinyal dengan frekuensi audio dengan sumber informasi dari laptop kemudian masuk pada block transmitter (Tx), sinyal informasi dikuatkan menggunakan rangkaian audio transformator yang memiliki nilai impedansi $1000 \mathrm{Ohm}$ dan transistor jenis NPN D13009 serta sumber baterai 3,7 Volt. Sinyal informasi dipancarkan menggunakan cahaya tampak dari laser led $5 \mathrm{~mW}$. Jika sumber tegangan $>4 \mathrm{~V}$ lanjut ke pengukuran tegangan laser LED jika tidak maka perlu penguatan lagi. Langkah selanjutnya mengukur tegangan laser LED untuk memastikan laser LED on atau off, jika off maka cek rangkaian tegangan, jika tidak maka informasi bisa ditransmisikan.

Sinyal informasi kemudian diterima dibagian receiver berupa solar panel mini. Sinyal informasi diterima oleh solar panel mini $5 \mathrm{~V} 220 \mathrm{~mA}$ dengan ukuran $13 \mathrm{~cm}$ x $6 \mathrm{~cm}$. lanjut ke bagian penguatan menggunakan modul amplifier mini class D PAM $861015 \mathrm{~W}$ agar sinyal suara yang diterima tetap dengan kualitas yang baik. Audio kemudian keluar melalui speaker, jika tidak maka cek kembali rangkaian di bagian sisi penerima.
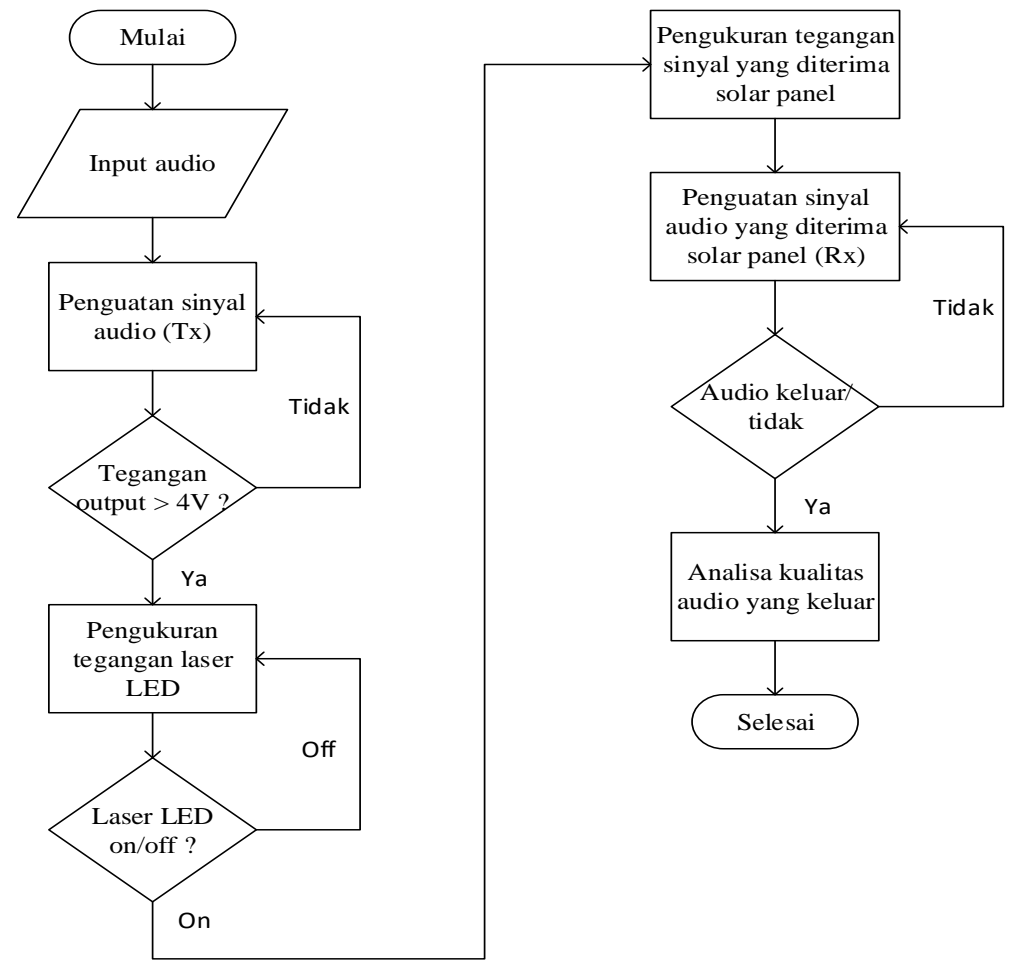

Gambar 3. Diagram Alir Penelitian 
Perancangan alat ini terdiri dari bagian transmitter dan receiver. pada bagian transmitter dibuat rangkaian penguat audio menggunakan audio trafo dan transistor terlebih dahulu pada papan board . Setelah rangkaian berfungsi dengan baik rangkaian dibuat pada PCB. Sedangkan pada receiver menggunakan modul kit amplifier mini PAM8610.

\subsection{Perancangan Transmitter}

Komponen yang dibutuhkan pada perancangan transmitter adalah audio transformator dengan impedansi $1000 \mathrm{ohm}$, transistor NPN D13009, laser 5mW, kabel audio, dan baterai tipe 18650 3,7V sebagai sumber tegangan supply transmitter VLC. Gambar 4 menunjukan skema dari rangkaian transmitter VLC. Input jack audio negatif dihubungkan pada input trafo dengan nilai 0 untuk ground, jack audio positif left dan right di hubungkan pada trafo dengan nilai impedansi sebesar $8 \mathrm{Ohm}$. Kutub positif dari laser led di hubungkan pada kaki resistor dan emitter transistor, kaki base transistor dihubungkan ke trafo yang memliki nilai impedansi sebesar $1000 \mathrm{ohm}$ pada output trafo, kaki collector transistor dihubungkan pada kutub positif baterai 3,7 V, kutub negative baterai dihubungkan ke kutub negative laser, kapasitor dan sisi 0 dari output trafo.
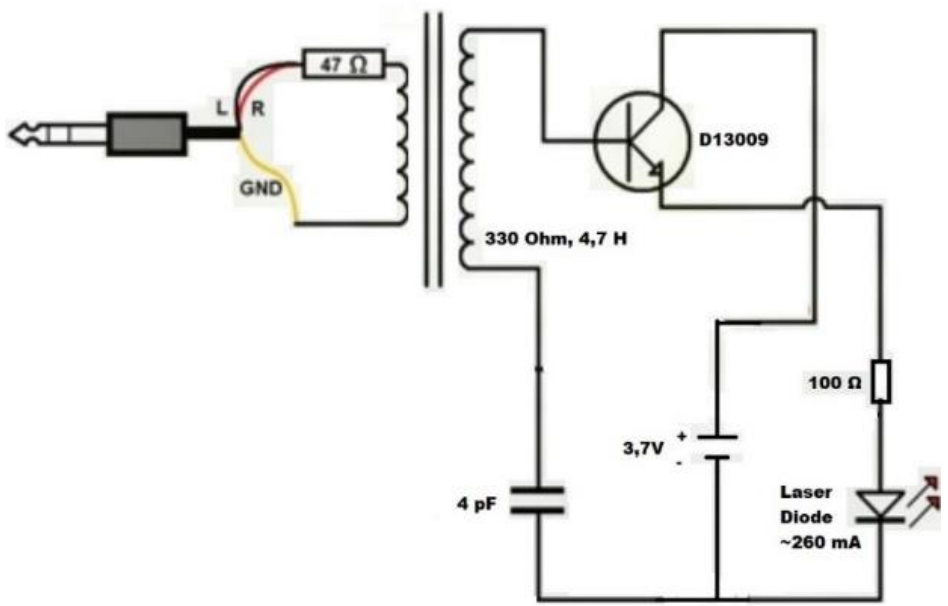

\subsection{Perancangan Receiver VLC}

Gambar 4. Skema Rangkaian Transmitter VLC

Komponen yang digunakan pada rangkaian receiver VLC yaitu pada solar panel kit sebagai penerima sinyal yang dikirimkan melalui laser led, penguatan sinyalnya menggunakan modul PAM 8610 dan output berupa speaker.

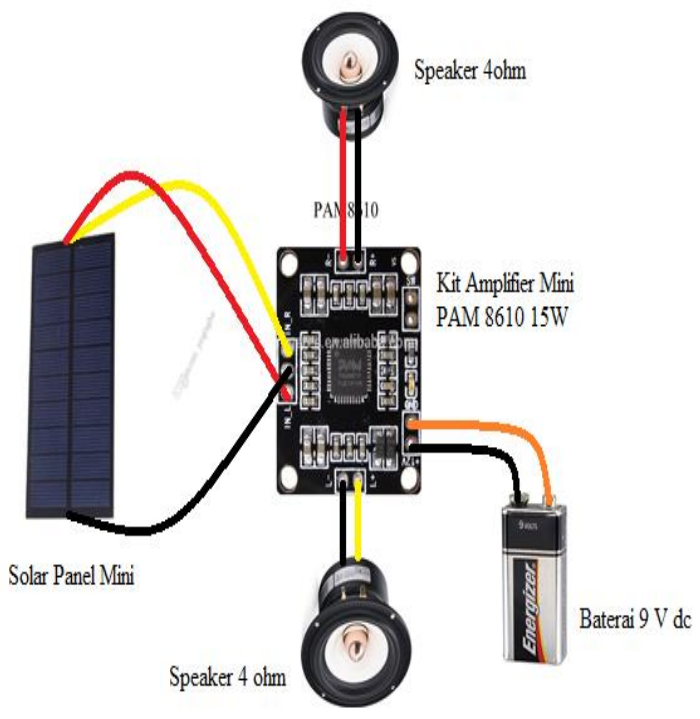

Gambar 5. Skema Rangkaian Receiver VLC 
Skema dari rangkaian receiver VLC pada Gambar 5. Solar panel kutub positif dihubungkan ke pin right dan left input kit amplifier PAM8610, supply tegangan baterai positf dan negative dihubungkan ke pin input tegangan kit amplifier PAM 8610, output sinyal dikeluarkan melalui pin output yang dihubungkan ke speaker left dan right. Pada pengiriman sinyal cahaya tampak, untuk kondisi cahaya ruangan masih dapat diterima oleh receiver dengan baik yaitu 30-300 lux untuk aktivitas visual normal[15].

\section{Hasil dan Pembahasan}

\subsection{Pengukuran Jarak Pengiriman Sinyal}

Pada pengukuran jarak pengiriman sinyal audio dilakukan di indoor pada saat kondisi ruangan terang dengan intensitas cahaya 078 Lux dan gelap sebesar 001 Lux . Frekuensi audio input berupa gelombang sinusoidal dengan frekuensi $1 \mathrm{KHz}$ menggunakan software NHC Tone Generator. Volume diatur sebesar $80 \%$ pada kondisi terang maupun gelap, informasi audia masih bias diterima dengan jarak maksimal 11 meter. Namun untuk kualitas suara yang diterima berbeda antara kondisi terang dan gelap. Pada kondisi terang, kualitas suara yang dikeluarkan oleh speaker yaitu 98,7 dB sedangkan pada kondisi gelap 98,3 dB. Pada kondisi terang, dari segi kualitas suara memang lebih besar dari kondisi gelap namun pada saat suara keluar akan terdengar berupa dengung karena efek cahaya lain yang masuk pada solar panel. Lain halnya pada kondisi gelap, cahaya hanya berasal dari laser led saja, suara yang terdengarpun lebih jelas namun dengan kualitas suara yang di bawah kondisi terang. Hasil penelitian ini lebih baik dari sebelumnya yang mengirimkan suara pada jarak 2,5 $\mathrm{m}[16]$.

\subsection{Pengukuran Kualitas Suara Sistem VLC}

Pengukuran kualitas suara sistem VLC dengan menvariasikan jarak Tx ke Rx menggunakan soundmeter. Pemancar pada output transmitter (tx) laser diarahkan secara line of sight pada solar panel receiver (rx) dengan jarak maksmial pengukuran $500 \mathrm{~cm}$ dalam kondisi ruangan terang dan gelap. Pada pengukuran kualitas suara sistem VLC kondisi terang, intensitas cahaya yang terukur pada alat lux meter yaitu 079 lux. Berikut Tabel 2 pengukuran kualitas suara dalam kondisi terang menggunakan sound level meter.

Tabel 2. Pengukuran Kualitas Suara Sistem VLC Kondisi Terang

\begin{tabular}{ccc}
\hline Jarak $(\mathrm{cm})$ & Kualitas Suara $(\mathrm{dB})$ & Intensitas Lux \\
\hline 50 & 97,9 & 079 \\
100 & 96,9 & 079 \\
150 & 96,1 & 079 \\
200 & 95,6 & 079 \\
250 & 94,7 & 079 \\
300 & 93,3 & 079 \\
350 & 92,7 & 079 \\
400 & 92,5 & 079 \\
450 & 98,4 & 079 \\
500 & 99,1 & 079
\end{tabular}

Tabel 2 memperlihatkan hasil pengukuran kualitas suara sistem VLC pada kondisi terang di jarak $50-500 \mathrm{~cm}$. Kualitas suara yang dihasilkan dengan memvariasikan jarak antara Tx dan RX pun bervariasi. Pada jarak awal $50 \mathrm{~cm}$, kualitas suara sebesar 97,9 dB. Sampai pada jarak $400 \mathrm{~cm}$, kualitas suara justru semakin kecil dengan kualitas sebesar 92,5 dB di jarak $400 \mathrm{~cm}$. Namun pada jarak 450- $500 \mathrm{~cm}$, kualitas suara mengalami kenaikan, yaitu 99,1 dB pada jarak $500 \mathrm{~cm}$. pada jarak 50-400 cm, cahaya yang diterima oleh solar panel masih dalam bentuk cahaya lurus dari laser Led dan bersifat fokus.

Pada pengukuran kualitas suara sistem VLC kondisi gelap, intensitas cahaya yang terukur pada alat lux meter yaitu 001 lux. Berikut Tabel 3 pengukuran kualitas suara dalam kondisi gelap menggunakan sound level meter. 
Tabel 3. Pengukuran Kualitas Suara Sistem VLC Kondisi Gelap

\begin{tabular}{ccc}
\hline Jarak $(\mathrm{cm})$ & Kualitas Suara $(\mathrm{dB})$ & Intensitas Lux \\
\hline 50 & 97,9 & 001 \\
100 & 95,6 & 001 \\
150 & 95,1 & 001 \\
200 & 94,2 & 001 \\
250 & 93,3 & 001 \\
300 & 94,1 & 001 \\
350 & 96,3 & 001 \\
400 & 97,9 & 001 \\
450 & 98,3 & 001 \\
500 & 99,2 & 001 \\
\hline
\end{tabular}

Hasil pengukuran kualitas suara dari sistem VLC pada Tabel 3 dalam kondisi gelap dengan jarak $50 \mathrm{~cm}-500 \mathrm{~cm}$. Kualitas suara jarak $50 \mathrm{~cm}$ yaitu sebesar 97,9 dB, ketika jaraknya semakin jauh ternyata hasil kualitas suara semakin menurun. Pada jarak $250 \mathrm{~cm}$, kualitas suara terukur 93,3 dB akan tetapi pada jarak $350 \mathrm{~cm}$ kualitas suara bahkan mengalami kenaikan menjadi 96,3 dB. Mulai jarak $350 \mathrm{~cm}-500 \mathrm{~cm}$, kualitas suara semakin mengalami kenaikan. Kualitas suara terbaik dengan jarak $500 \mathrm{~cm}$ sebesar 99,2 dB. Pada kondisi gelap dengan jarak terjauh $500 \mathrm{~cm}$, kualitas suara yang dihasilkan lebih bagus dibandingkan dengan kondisi terang. Hal ini terjadi karena pada saat kondisi terang, ada interferensi cahaya lain yang masuk ke solar panel sehingga mempengaruhi kualitas suara yang dihasilkan. Sedangkan pada kondisi gelap, solar panel hanya menerima cahaya dari laser Led saja dan pancarannya pun juga lebih fokus.

\subsection{Pengukuran Kualitas Suara Terhadap Sudut Pancar Sistem VLC}

Pengukuran kualitas suara terhadap perubahan sudut sistem VLC ini, dilakukan pada kondisi ruangan terang dan gelap. Posisi awal Tx terhadap Rx yakni di sudut $90^{\circ}$ karena posisi ini berada line of sight antar $\mathrm{Tx}$ dan Rx. Pengukuran kualitas suara dilakukan dengan memvariasikan sudut pancar di $70^{\circ}, 80^{\circ}, 90^{\circ}, 100^{\circ}$ dan $110^{\circ}$. Hal ini dilakukan untuk membandingkan hasil kualitas suara ketika posisi line of sight dengan posisi Tx dan Rx yang tidak sejajar. Berikut Tabel 4 pengukuran kualitas terhadap perubahan sudut pemancaran pada kondisi terang menggunakan sound level meter.

Tabel 4. Pengukuran Kualitas Suara Terhadap Sudut Pancar Kondisi Terang

\begin{tabular}{cccc}
\hline Sudut & Jarak $(\mathrm{cm})$ & Intensitas Lux & Kualitas Suara $(\mathrm{dB})$ \\
\hline \multirow{4}{*}{$70^{\circ}$} & 50 & 078 & 96 \\
& 100 & 078 & 94,1 \\
& 150 & 078 & 0 \\
& 200 & 078 & 0 \\
& 50 & 078 & 0 \\
$80^{\circ}$ & 100 & 078 & 97,1 \\
& 150 & 078 & 94,7 \\
& 200 & 078 & 96,7 \\
& 250 & 078 & 0 \\
$90^{\circ}$ & 100 & 078 & 0 \\
& 150 & 078 & 97,9 \\
& 200 & 078 & 96,9 \\
& 250 & 078 & 96,1 \\
$100^{\circ}$ & 100 & 078 & 95,6 \\
& 150 & 078 & 94,7 \\
& 200 & 078 & 97,4 \\
& 250 & 078 & 94,8 \\
& & 078 & 0
\end{tabular}




\begin{tabular}{cccc}
\hline Sudut & Jarak $(\mathrm{cm})$ & Intensitas Lux & Kualitas Suara $(\mathrm{dB})$ \\
\hline \multirow{4}{*}{$110^{\circ}$} & 50 & 078 & 96,3 \\
& 100 & 078 & 94 \\
& 150 & 078 & 0 \\
& 200 & 078 & 0 \\
\hline
\end{tabular}

Tabel 4 memperlihatkan hasil pengukuran kualitas suara kondisi terang terhadap perubahan sudut pancar dari transmitter posisi awal di sudut $90^{\circ}$ secara line of sight. Ternyata, kualitas suara yang terbaik berada di sudut $90^{\circ}$ sebesar $97,9 \mathrm{~dB}$ dengan jarak $50 \mathrm{~cm}$. Rata-rata pada jarak terjauh yaitu $150 \mathrm{~cm}$, sinyal informasi yang masih dapat diterima dengan baik. Lain halnya ketika jarak $250 \mathrm{~cm}$ di sudut $70^{\circ}, 80^{\circ}, 90^{\circ}, 100^{\circ}$ dan $110^{\circ}$. Kualitas suara yang terukur sebesar 0 $\mathrm{dB}$ sedangkan di sudut $90^{\circ}$ tetap dengan kualitas suara yang baik yaitu 94,7 dB. Berikut Tabel 5 pengukuran kualitas terhadap perubahan sudut pemancaran pada kondisi gelap menggunakan sound meter.

Tabel 5. Pengukuran Kualitas Suara Terhadap Sudut Pancar Kondisi Gelap

\begin{tabular}{|c|c|c|c|}
\hline Sudut & $\begin{array}{l}\text { Jarak } \\
(\mathrm{cm})\end{array}$ & $\begin{array}{c}\text { Intensitas } \\
\text { lux }\end{array}$ & $\begin{array}{c}\text { Kualitas } \\
\text { suara }(\mathrm{dB})\end{array}$ \\
\hline \multirow{5}{*}{$70^{\circ}$} & 50 & 001 & 97,6 \\
\hline & 100 & 001 & 96 \\
\hline & 150 & 001 & 0 \\
\hline & 200 & 001 & 0 \\
\hline & 250 & 001 & 0 \\
\hline \multirow{5}{*}{$80^{\circ}$} & 50 & 001 & 98 \\
\hline & 100 & 001 & 96,5 \\
\hline & 150 & 001 & 94,9 \\
\hline & 200 & 001 & 0 \\
\hline & 250 & 001 & 0 \\
\hline \multirow{5}{*}{$90^{\circ}$} & 50 & 001 & 97,9 \\
\hline & 100 & 001 & 95,6 \\
\hline & 150 & 001 & 95,1 \\
\hline & 200 & 001 & 94,2 \\
\hline & 250 & 001 & 93,3 \\
\hline \multirow{5}{*}{$100^{\circ}$} & 50 & 001 & 98,1 \\
\hline & 100 & 001 & 96,3 \\
\hline & 150 & 001 & 94,7 \\
\hline & 200 & 001 & 0 \\
\hline & 250 & 001 & 0 \\
\hline \multirow{5}{*}{$110^{\circ}$} & 50 & 001 & 97,7 \\
\hline & 100 & 001 & 96,1 \\
\hline & 150 & 001 & 0 \\
\hline & 200 & 001 & 0 \\
\hline & 250 & 001 & 0 \\
\hline
\end{tabular}

Hasil Pengukuran kualitas suara pada Gambar 5 dengan kondisi terang terhadap perubahan sudut pancar dari transmitter posisi awal di sudut $90^{\circ}$ secara line of sight. Hasil pengukuran kualitas suara pada kondisi gelap tidak jauh berbeda dengan kondisi terang. Pada kondisi gelap, justru tidak di sudut yang line of sight kualitas suara yang terbaik. Kualitas suara terbaik di sudut $100^{\circ}$ dengan jarak $50 \mathrm{~cm}$ sebesar $98,1 \mathrm{~dB}$ sedangkan pada posisi line of sight $\left(90^{\circ}\right)$ dengan jarak $50 \mathrm{~cm}$ sebesar 97,9 dB. Rata-rata jarak terjauh yang sinyal informasi masih dapat diterima sejauh $150 \mathrm{~cm}$. Sedangkan di jarak $200 \mathrm{~cm}$, sinyal informasi mulai tidak bisa diterima karena dimensi dari solar panel sebagai penerima hanya hanya $13 \mathrm{~cm}$ x $6 \mathrm{~cm}$. 


\subsection{Pengukuran Gain VLC}

Input sinyal berupa sinusoidal dari function generator dengan frekuensi $1 \mathrm{KHz}-10 \mathrm{Khz}$. Bagian Input dihubungkan ke input Tx dengan jarak ke Rx sejauh $100 \mathrm{~cm}$. Tegangan Vp-p output dari transmitter dan receiver terdapat pada Tabel 6. Tegangan output Tx sebesar 5,5 Vp$\mathrm{p}$ dan tegangan output $\mathrm{Rx} 11,5 \mathrm{Vp}-\mathrm{p}$ pada oscilloscope. Nilai pengukuran tegangan ini untuk menghitung gain dari sistem VLC. Berdasarkan perhitungan, diperoleh gain sebesar 6,40 dB.

Tabel 6. Pengukuran Gain Sistem VLC

\begin{tabular}{cccc}
\hline $\begin{array}{c}\text { Frekuensi Input Funtion } \\
\text { Generator }(\mathrm{KHz})\end{array}$ & $\begin{array}{c}\text { Tegangan Output Tx } \\
(\mathrm{Vp}-\mathrm{p})\end{array}$ & $\begin{array}{c}\text { Tegangan Output Rx } \\
(\mathrm{Vp}-\mathrm{p})\end{array}$ & $\begin{array}{c}\text { Gain Receiver } \\
(\mathrm{dB})\end{array}$ \\
\hline 1 & 5,5 & 11,5 & 6,40 \\
2 & 5,5 & 11,5 & 6,40 \\
3 & 5,5 & 11,5 & 6,40 \\
4 & 5,5 & 11,5 & 6,40 \\
5 & 5,5 & 11,5 & 6,40 \\
6 & 5,5 & 11,5 & 6,40 \\
7 & 5,5 & 11,5 & 6,40 \\
8 & 5,5 & 11,5 & 6,40 \\
9 & 5,5 & 11,5 & 6,40 \\
10 & 5,5 & 11,5 & 6,40 \\
\hline
\end{tabular}

Berikut hasil perhitungan untuk gain $(G)$ tegangan menggunakan persamaan (1)

Pengukuran gain receiver

$\mathrm{G}=20 \log ($ Pout $/$ Pin $)$

$=20 \log (11,5 / 5,5)$

$=6,40 \mathrm{~dB}$

\section{Kesimpulan}

Prototype transceiver VLC laser led dapat digunakan sebagai media transmisi komunikasi tanpa kabel. VLC mampu mengirim sinyal informasi dengan jarak maksimal yaitu 11 meter terukur 98,7 dB yang lebih jauh dari sebelumnya 2,5 meter. Kualitas suara yang dihasilkan pada kondisi ruangan terdapat sedikit noise atau dengung dibandingkan dengan kondisi gelap karena ada efek dari cahaya lain yang masuk ke solar panel. Variasi jarak antara transmitter dan receiver mempengaruhi kualitas suara yang diterima. Pada jarak $500 \mathrm{~cm}$ di kondisi gelap, kualitas suara yaitu 99,2 dB pada kondisi terang dan 99,1 dB. Perubahan sudut pancar Tx terhadap Rx mempengaruhi hasil kualias suara. Kualitas suara terbaik pada sudut $90^{\circ}$ di kondisi terang dengan jarak $50 \mathrm{~cm}$ sebesar 97,9 dB sedangkan di kondisi gelap dengan jarak $50 \mathrm{~cm}$ pada sudut $100^{\circ}$ sebesar 98,1 dB. Gain sistem VLC ini sebeasr 6,40 dB yang hasilnya lebih baik dibandingkan penelitian sebelumnya sebesar $2 \mathrm{~dB}$.

\section{Daftar Pustaka}

[1] B. D. Larry Peterson, Computer Network, 6th ed. Morgan Kaufmann, 2020.

[2] V. Y. P. Bokau, "Lifi: Teknologi Komunikasi Nirkabel Masa Depan," J. Ilm. Realt., vol. 14, no. 1, pp. 103-109, 2018, doi: 10.52159/realtech.v14i1.125.

[3] A. Rifiandi, A. Hambali, A. D. Pambudi, and F. T. Elektro, "Perancangan \& Implementasi Visible Light Communication Untuk Komunikasi Radio Fm Design \& Implementation Visible Light Communication," e-Proceeding Appl. Sci., vol. 4, no. 3, pp. 3557-3564, 2017.

[4] G. Hendana, "Perancangan dan Realisasi Komunikasi Suara Dua Arah Melalui Media Sinar Laser Menggunakan Modulasi FM dan PLL," 2018.

[5] T. Adiono, S. Fuada, and A. Pradana, "Desain dan Realisasi Sistem Komunikasi Cahaya Tampak untuk Streaming Teks berbasis PWM," Setrum Sist. Kendali-Tenaga-elektronikatelekomunikasi-komputer, vol. 6, no. 2, p. 270, 2017, doi: 10.36055/setrum.v6i2.2620.

[6] I. L. R. and M. Á. G.C. García, "State of the Art, Trends and Future of Bluetooth Low 
Energy, Near Field Communication and Visible Light Communication in the Development of Smart Cities," MDPI Sensors J., vol. 16, pp. 1-38, 2016, doi: 10.3390/s16111968.

[7] S. Fuada, "Design and Implementation of Analog Front-End Transceiver Module for Visible Light Communication System," Institut Teknologi Bandung, Bandung, 2017.

[8] S. Fuada and T. Adiono, "Rancang Bangun Layer Fisik Visible Light Communication Pada Sistem Transmisi Audio," J. Infotel, vol. 9, no. 3, pp. 352-360, 2017, doi: 10.20895/infotel.v9i3.288.

[9] F. M. F. dan E. M. Agustini, S. Oktaviani and Mozef, "Perancangan dan Realisasi Sistem Komunikasi Suara dengan Penjelasan Suara yang Ditransmisikan dari Cahaya Lampu Penerangan LED," in IRWNS, 2019, pp. 387-395.

[10] T. Muhammad, R. Handzalah, D. Darlis, and D. M. Saputri, "Simulasi Komunikasi Cahaya Tampak Berbasis Pemultipleksan Pembagian Panjang Gelombang pada Jaringan Fiber to the Home Simulasi Komunikasi Cahaya Tampak Berbasis Pemultipleksan Pembagian Panjang Gelombang pada Jaringan Fiber to the Home," SENIATI ITENAS Malang, no. April, pp. 388-393, 2019.

[11] N. Azizah, G. A. Khoirunnisa, N. Nuzulia, R. S. Muhammad, and M. Su'udi, "Review: Mekanisme Miko-Heterotrof Tumbuhan Monotropa," JRST (Jurnal Ris. Sains dan Teknol., vol. 3, no. 2, p. 49, 2020, doi: 10.30595/jrst.v3i2.4142.

[12] Ramalia Noratama Putri and D. Setiawan, "Prediksi Penyakit Systemic Lupus Erythematosus Menggunakan Algoritma Genetika," Digit. Zo. J. Teknol. Inf. dan Komun., vol. 12, no. 1, pp. 19-31, 2021, doi: 10.31849/digitalzone.v12i1.5973.

[13] et. al S. Dong, "A Voice Transmission System Based on Visible Light Communication," in Proc. of the IEEE 5th Global Conf. on Consumer Electronics, 2016, pp. 1-2.

[14] A. Charisma, "Implementasi Sistem Komunikasi FM pada Prototype Pendeteksi Dini Gempa," PROtek J. Ilm. Tek. Elektro, vol. 7, no. 2, pp. 60-64, 2020.

[15] Wisnu and M. Indarwanto, "Evaluasi Sistem Pencahayaan Alami Dan Buatan Pada Ruang Kerja Kantor Kelurahan Paninggilan Utara, Ciledug, Tanggerang.," J. Arsitektur, Bangunan, Lingkung., vol. 7, pp. 41-46, 2017.

[16] A. R. Darlis and D. Adrian, "Traffic Light Systems Menggunakan Visible Light Communication (Vlc) Sebagai Alat Bantu Tunanetra Untuk Menyeberang Jalan," TESLA J. Tek. Elektro, vol. 22, no. 1, p. 34, 2020, doi: 10.24912/tesla.v22i1.7770.

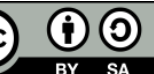

Digital Zone: Jurnal Teknologi Informasi dan Komunikasi is licensed under a_Creative Commons Attribution International (CC BY-SA 4.0) 